\title{
Human osteoblast stimulation by sera from paraplegic patients with heterotopic ossification
}

\author{
M H J Kurer MBBS BSc FRCS, ${ }^{1}$ M A Khoker BSc MSc PhD,${ }^{2} \mathrm{P}$ Dandona PhD, \\ $\mathrm{FRCP}^{2}$ \\ ${ }^{1}$ The Royal National Orthopaedic Hospital, Brockley Hill, Stanmore, Middlesex, HA7 \\ $4 L P$, England; ${ }^{2}$ Department of Chemical Pathology and Human Metabolism, Royal Free \\ Hospital School of Medicine, Pond Street, London NW3 2QJ, England.
}

\begin{abstract}
The pathophysiology of heterotopic periarticular ossification is not understood. Though local agents may be responsible, factors present in the serum may be contributory. Sera from 4 paraplegic patients with heterotopic ossification and 4 'normal' paraplegics were incubated with human osteoblasts in tissue culture and their metabolic acitivy was measured quantitatively. There were significantly greater levels of osteoblast stimulating factors present in the sera of ossifying patients, $(p<0.01)$. These factors may contribute to the pathogenesis of heterotopic ossification.
\end{abstract}

Key words: paraplegia; heterotopic ossification; osteoblast; hormone.

\section{Introduction}

Heterotopic periarticular ossification is a disease which affects a proportion of patients who have suffered spinal cord injury. In affected patients new bone forms in the capsule and muscles surrounding the affected joint, causing pain and preventing movement. Though several risk factors have been described the pathophysiology has not been elucidated. Though local factors contribute to the process a systemic hormonal amplification may be present.

Recently it has become possible to grow human osteoblasts in tissue culture. This has allowed investigation of the effects of hormones, drugs or other factors on osteoblast growth and metabolic activity.
The aim of this study was to determine whether patients with heterotopic ossification had increased levels of hormones stimulatory to osteoblasts in the serum, which might predispose to or even cause periarticular ossification.

\section{Patients and methods}

Serum was taken from the following groups of patients (Table I):

1 Four patients rendered paraplegic after spinal injury with heterotopic periarticular ossification and mobile in wheelchairs (3 males and 1 female, aged 26 to 45 years). Blood samples were taken between 4 and 7 months after injury.

Table 1 Patient details

\begin{tabular}{|c|c|c|c|c|c|c|c|c|}
\hline \multicolumn{3}{|c|}{ Age (yrs) } & \multicolumn{3}{|c|}{ Sex } & \multicolumn{2}{|c|}{ Lesion level } & \multirow{2}{*}{$\frac{\text { Joint affected }}{(\mathrm{HO})}$} \\
\hline $\mathrm{HO}$ & $\mathrm{P}$ & $\mathrm{C}$ & $\mathrm{HO}$ & $\mathrm{P}$ & $\mathrm{C}$ & $\mathrm{HO}$ & $\mathrm{P}$ & \\
\hline 26 & 24 & 24 & $\mathrm{M}$ & $\mathrm{M}$ & $\mathrm{M}$ & C5 & C5 & Elbow \\
\hline 33 & 35 & 33 & M & M & M & C5 & C6 & Hip \\
\hline 39 & 36 & 38 & $\mathrm{M}$ & M & $\mathrm{M}$ & D7 & D6 & Hip \\
\hline 45 & 45 & 43 & $\mathrm{~F}$ & $\mathrm{~F}$ & $\mathrm{~F}$ & D12 & D12 & Hip \\
\hline
\end{tabular}

$\mathrm{HO}=$ paraplegic patients with heterotopic ossification, $\mathrm{P}=$ paraplegic patients without heterotopic ossification, $\mathrm{C}=$ healthy volunteers (controls). 
2 Four paraplegic patients mobile in wheelchairs with similar spinal injuries to patients in group (1), but without heterotopic ossification ( 3 males and 1 female, aged 24 to 45 years). Blood samples were taken between 5 and 7 months after injury.

3 Four healthy age and sex matched volunteers.

None of the above patients was taking corticosteroids, nonsteroidal anti-inflammatory drugs, diphosphonates or vitamin supplements. All the paraplegic patients had complete lesions and none had pressure sores. Informed consent was obtained from all patients before collection of blood for this study.

\section{Cell culture}

The technique has been described in detail by Gallagher ${ }^{1}$ but, briefly, consists of the following stages. Osteoblasts are harvested from the heads of femurs taken at total hip replacement. The cells are cultured in standard medium until they have formed a monolayer in Petri dishes. They are then suspended in solution such that aliquots containing known numbers of cells can be separated into culture wells. Test sera are then incubated with the osteoblasts and the alkaline phosphatase secreted by the cells into the solution is measured. Tritiated Thymidine is then added for 12 hours. The cells are then removed from the culture medium and the Thymidine uptake is measured. Three different concentrations of serum are tested and each experiment is done in quadruplicate.

The Mann-Whitney (two-tailed) test was performed for all statistical comparisons.

\section{Results}

Human osteoblasts in tissue culture released ALP in significant amounts. A dosedependent increase in ALP secretion and $3_{\mathrm{H}}$-Thymidine uptake by osteoblasts was seen following incubation with various concentrations of control sera (Figs 1 and 2). There was significantly greater alkaline phosphatase secretion and ${ }^{3} \mathrm{H}$-Thymidine uptake when osteoblasts were incubated sera from paraplegic patients without ec- topic ossification $(p<0.05)$. This occurred at $20 \%$ dilution. Sera from paraplegic patients with heterotopic ossification were much more stimulatory than both the healthy volunteers and the paraplegics without heterotopic ossification at all dilutions $(p<0.01)$. Sera had a more profound effect

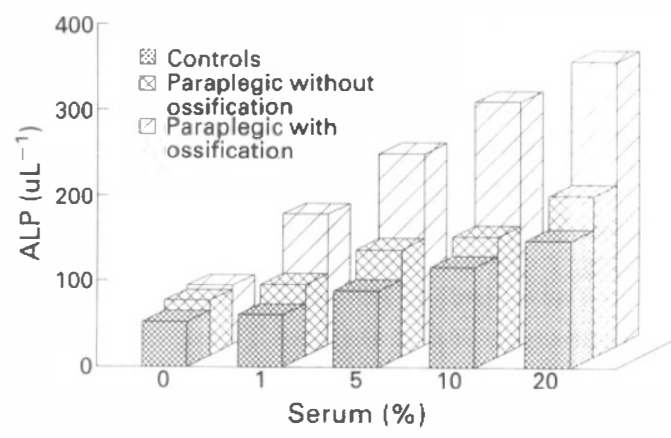

Figure 1 The effect of sera on alkaline phosphatase (ALP) production on human osteoblasts in tissue culture. Sera from paraplegic patients were more stimulatory than control sera at $20 \%$ dilution $(p<0.05)$. Sera from paraplegic patients with heterotopic ossification produced significantly greater stimulation at all $(1-20 \%)$ dilutions $(p<0.01)$, than the other 2 groups. The Standard Errors were less than 40 units/litre in all samples.

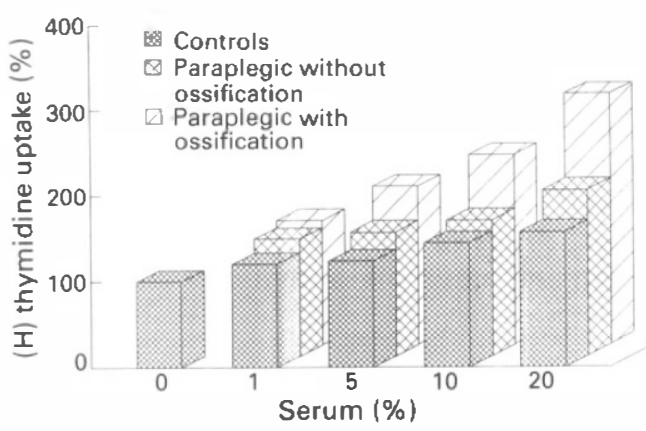

Figure 2 The effect of sera on ${ }^{3} \mathrm{H}$-Thymidine uptake on human osteoblast in tissue culture. Sera from paraplegic patients were more stimulatory than control sera at $20 \%$ dilution $(p<0.05)$. Sera from paraplegic patients with heterotopic ossification produced significantly greater uptake at 5,10 and $20 \%$ dilutions $(p<0.01)$, than the other 2 groups. The Standard Errors were less than $25 \%$ in all samples. 
on alkaline phosphatase secretion than ${ }^{3} \mathrm{H}$ Thymidine uptake.

\section{Discussion}

Heterotopic periarticular ossification affects between 15 and $45 \%$ of paraplegics. ${ }^{2}$ It occurs more commonly after complete spinal cord lesions and affects joints distal to the level of injury. ${ }^{3}$ The wrist and fingers and the ankle and foot are seldom affected. ${ }^{4}$ There is no difference in the incidence between flaccid and spastic patients, nor is it associated with the formation of renal stones. ${ }^{5}$ Local decubitus ulceration predisposes to ossification but this is considered a separate clinical group. ${ }^{6}$ Silver $^{7}$ suggested that excessive joint manipulation was a cause, but in the majority of spinal units physiotherapy regimes are standardised. Furthermore, manipulation studies on paraplegic rabbits failed to produce heterotopic bone, ${ }^{8}$ and the occurrence of ossification in association with other examples of neurological injury such as head injury, tetanus and anterior poliomyelitis is also not explained. ${ }^{6}$

Serum alkaline phosphatase levels are invariably elevated ${ }^{9}$ and the bone that is formed may not be completely mineral- ised $^{10}$ but has a collagen concentration similar to normal bone. ${ }^{11}$ There is an increased incidence of the antigens HLA B18 and HLA DRW7 in affected patients. ${ }^{12}$

The existence of hormones present in highly stimulatory amounts in the sera of affected patients is significant. These patients may secrete hormones which in the presence of local factors serve to trigger differentiation of connective tissue fibroblasts to osteoblasts and bone formation. Stimulation of osteoblasts in vitro by sera from patients with severe head injury has also been noted (unpublished findings) as well as the suppression of stimulation by diphosphonates. ${ }^{13}$ This is noteworthy since these drugs have been found to be of value in the treatment and prevention of heterotopic ossification. ${ }^{14}$ These drugs may act by suppressing the activity of cells which have been stimulated by hormonal factors. Various authors have suggested the existence of both systemic and local factors and these experimental findings support this hypothesis.

\section{Acknowledgements}

The authors would like to thank Dr H Frankel and the patients at Stoke Mandeville hospital for their help and support with this project.

\section{References}

1 Gallagher HA, Beresford JN, Sharrad M (1983) Human bone cells in culture: a novel system for the study of osteoblast function. Calcif Tissue Int 35 (supp A): 24.

2 Chantraine A and Minaire P (1981) Para-osteo-arthropathies, a new theory and mode of treatment. Scand J Rehabil Med 13: 31-37.

3 Lal S, Heinemann A, Hamilton B (1989) Risk factors for heterotopic ossification in spinal cord injured. Paraplegia 27: 151-152.

4 Chantraine A (1978) Actual concept of osteoporosis in paraplegia. Paraplegia 16, 51-58.

5 Hernandez AM, Forner JV, De La Fuente T, Gonazalez C, Miro R (1978) The para-articular ossifications in our paraplegics and tetraplegics: a survey of 704 patients. Paraplegia 16: 272-275.

6 Couvee LMJ (1970) Heterotopic ossification and the surgical treatment of serious contractures. Paraplegia 7, 89-93.

7 Silver JR (1969) Heterotopic ossification. A clinical study of its possible relationship to trauma. Paraplegia 7: $220-230$.

8 Izumi K (1983) Study of ectopic bone formation in experimental spinal cord injured rabbits. Paraplegia 21: 351-363.

9 Bolger JT (1975) Heterotopic bone formation and alkaline phosphatase. Arch Phys Med Rehabil 56: 36-39.

10 Chantraine A (1971) Clinical investigation of bone metabolism in spinal cord lesions. Paraplegia 8: 253-259.

11 Lagier R, Gabbiani G (1973) Pathological study of para-osteo-arthropathy. In: AB Rossier, editor. Proceedings of a conference on para-osteo-arthropathy. Paraplegia 11: 63-78.

12 Minaire P, Meunier P, Edouard C, Bernard J, Courpron P, Bourret J (1974) Quantitative histological data on disuse osteoporosis. Calcif Tiss Int 17: 57-73. 
168 Kurer et al

13 Khoker MA, Dandona P (1989) Diphosphonates inhibit human osteoblast secretion and proliferation. Metabolism 38: 184.

14 Stover SL (1976) Disodium ethidronate in the prevention of heterotopic ossification following spinal cord injury. Paraplegia 14: 146-156. 